\title{
Virtual Worlds-Real Decisions: Model- and Visualization-based Tools for Landscape Planning in Switzerland
}

\author{
Authors: Walz, Ariane, Gloor, Christian, Bebi, Peter, Fischlin, Andreas, \\ Lange, Eckart, et. al. \\ Source: Mountain Research and Development, 28(2) : 122-127 \\ Published By: International Mountain Society \\ URL: https://doi.org/10.1659/mrd.0965
}

BioOne Complete (complete.BioOne.org) is a full-text database of 200 subscribed and open-access titles in the biological, ecological, and environmental sciences published by nonprofit societies, associations, museums, institutions, and presses.

Your use of this PDF, the BioOne Complete website, and all posted and associated content indicates your acceptance of BioOne's Terms of Use, available at www.bioone.org/terms-of-use.

Usage of BioOne Complete content is strictly limited to personal, educational, and non - commercial use. Commercial inquiries or rights and permissions requests should be directed to the individual publisher as copyright holder.

BioOne sees sustainable scholarly publishing as an inherently collaborative enterprise connecting authors, nonprofit publishers, academic institutions, research libraries, and research funders in the common goal of maximizing access to critical research. 
Ariane Walz

Christian Gloor

Peter Bebi

Andreas Fischlin

Eckart Lange

\section{Virtual Worlds-Real Decisions: Model- and Visualization-based Tools for Landscape Planning in Switzerland}

Prominent construction projects in Switzerland, such as the Sawiris luxury resort in Andermatt planned by Orascom Hotels \& Development, Cairo (Egypt), or the idea of a hotel and apartment tower at Schatzalp, Davos, demonstrate how rapidly Alpine landscapes may undergo major changes. Decisions on whether or not such changes are supported by policymakers should be based on the best information available and in agreement with the local population to ensure longterm sustainable development. The present article investigates the potential and limitations of computer-based tools to support such decisions in the area of landscape planning, with a particular focus on Alpine landscapes.

\section{Changes in the traditional Alpine landscape}

Traditional Alpine landscapes are considered to be one of the major elements of Switzerland's cultural heritage, as well as an important resource for national and international tourism. These landscapes have evolved over centuries of agricultural use. Nowadays, slow processes, such as changing cultivation patterns or gradual land abandonment, as well as high-impact interventions, eg extensive construction projects or infrastructure development, contribute to the rapid and profound alteration of Alpine landscapes (Box 1).

\section{Computer-based tools in landscape planning}

To make it easier to assess long-term effects in landscape planning, decisionmakers need the best information available. Computer-based tools are able to deal with the complexity of the decisions that need to be taken, and offer appropriate techniques to visualize and communicate relevant information. In the present article we distinguish between 2 types of computer-based tools:

\section{Large construction projects planned} in the Swiss Alps

- Sawiris luxury resort, Andermatt, Switzerland: "Egyptian tycoon plans Alpine oasis. [...] One of the Middle East's biggest hotel groups is on course to transform Andermatt into a luxury resort, complete with a golf course and a pool with its own sandy beach." (Imogen Foulkes, BBC News, 9 April 2007, http://news.bbc.co.uk)

Schatzalp Tower, Davos, Switzerland: “After a vote by the population of Davos on 10 October 2004, the local government decided upon alterations to local spatial planning in order to enable the construction of the 105-m high tower at the Schatzalp." (Translated from P. App, "Die Schatzalp—vom Zauberberg zum Zauberturm." Speech at the Summer University Davos 2007, 24 August 2007)

1. Models serve to generate and add information in the planning process. They are abstract and well-defined depictions of the real world that help us to break up and reconstruct complex systems (ie nature and society) 
and to predict their reaction as a response to external changes. In the context of landscape planning, they are often referred to as decision-support tools. Although they do not necessarily have to be computer-based, they often appear as software applications.

2. Visualization tools help to communicate complex information in a comprehensive, intuitive manner (Figure 1). Apart from well-processed graphs, such as diagrams, tables or maps, photorealistic or, in general, image-based depiction has become common in landscape planning. Visualization does not have to be computer-based. But the increasing availability of digital information and advances in visualization technology have made computerbased visualization a powerful and attractive tool.

Within the National Research Program NRP48 on "Landscapes and Habitats in the Alps," several projects focused on landscape modeling and visualization. These projects were brought together and discussed with regard to their contribution to the development of computerbased planning tools in Synthesis $\mathrm{V}$ of the NRP48 on virtual representation.

\section{Visualization in landscape planning}

Especially when visual qualities of the landscape are a key focus of the planning process, illustrations are needed, as planners and decision-makers must be able to see and to demonstrate to others how a development might change the appearance of the landscape. Visualization has been used for centuries, for instance in architecture, and is slowly playing a more important role also in landscape planning. From drawings and 3D cardboard models to photomontages, the latest developments in visualization technique are fully computer-generated views of the planned intervention.

Fully computer-generated visualization allows changing the viewpoint in an arbitrary way to reveal new perspectives. This can give completely new insights. For
FIGURE 2 Example of visualization of the planned visitor center for the Swiss National Park at Zernez, Canton of Grisons, Switzerland. (A) 3D model created by the architect, (B) profiles for the planned building, (C) computer-based simulation of the building. (Images courtesy of Pro Chaste da Zernez)
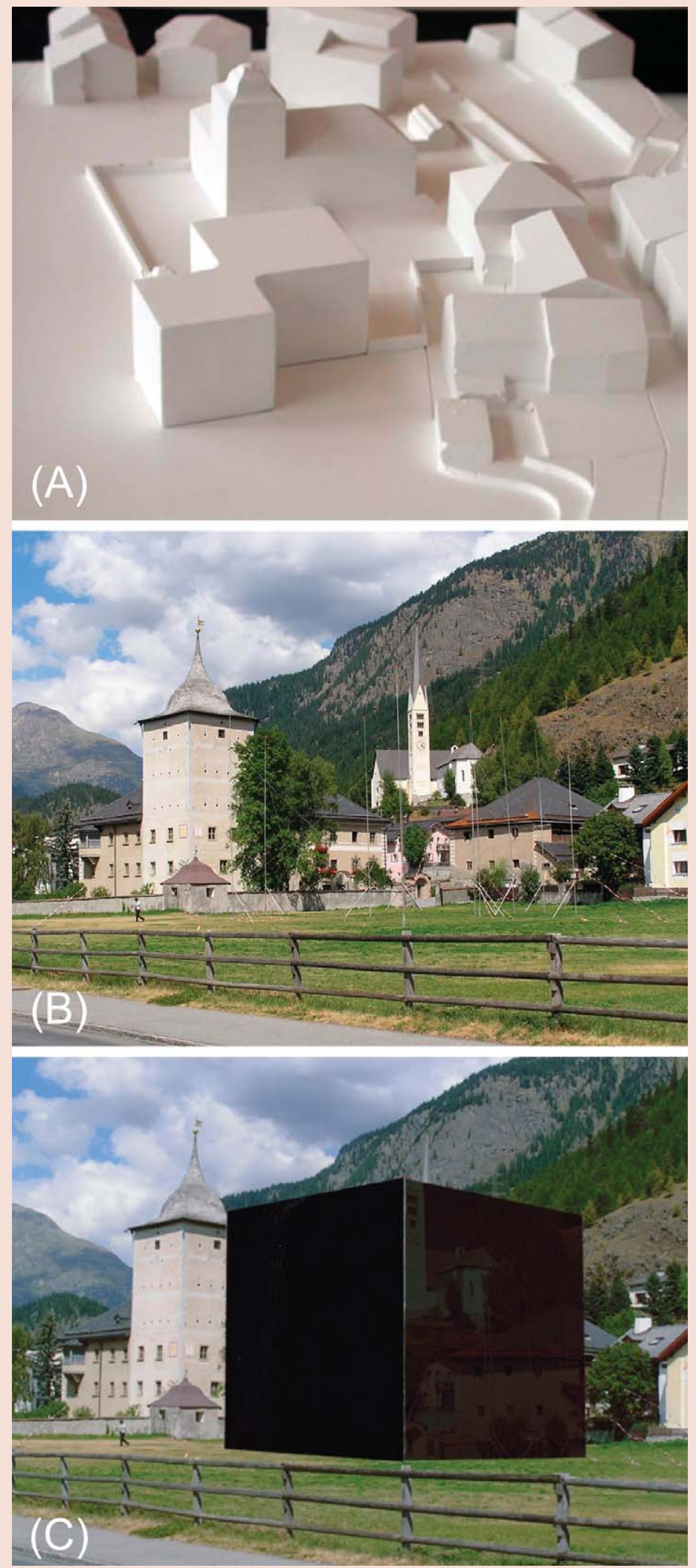


\section{Selected NRP48 modeling and visualization projects}

- ALPSCAPE: Within the ALPSCAPE project, future scenarios of regional development were simulated for the region of Davos, one of Switzerland's major tourist regions. A key focus was the integration of multiple modeling approaches, including 3 simulation models (economy, natural resources fluxes, land use) and a valuation tool (based on ecosystem services). Within a participatory process, the knowledge base was established to develop 3 scenarios influenced by agricultural policy, climate change, and the realization of a big sports event. Profound changes in agricultural policies showed the largest impact on the landscape, but economic consequences were minor compared to the impact of a climate change scenario with decreasing snow reliability. Among the evaluated ecosystem services, protection from snow avalanches by forests was the most important.

- ALPSIM: The model simulates hikers' behavior as a response to landscape change and interactions between them. The virtual hikers move in a virtual landscape with their plans and expectations, and they experience the landscape. At the end of the hiking day, their satisfaction is measured, and consequences are drawn from this satisfaction for the next day. The scenarios encompassed the expansion of forest and the closure of lifts and mountain railways over the summer in the study area of Schönried, near Gstaad. The project focused mainly on the methodological and technical aspects of agent-based modeling, visualization, and animation (Figure 3). It resulted in strong advances in computer realization, and revealed research gaps in the explanation of tourist behavior, and thus the knowledge base, needed to calibrate the model accurately.

- IPODLAS: Linking dynamic modeling with a Geographic Information System and real-time visualization was the overall, mainly technical objective of the project. By formulating detailed use cases, software architecture was developed that suited the requirements of several case studies. Besides a case study on wildfires, another case study looked at the migration patterns of the larch bud moth population in the Upper Engadine valley, Switzerland. In this case, the direct link between the spatiotemporal (ecological) model, the GIS and the visualization tool made it possible to study and visualize these migration patterns comfortably at different scales, ie from the entire Alpine arc to the extent of the Upper Engadine valley (Figure 4).

- SULAPS: A main focus was to identify the collective impact of multiple, independent "agents" (farmers) in response to changing agricultural policies. The model simulated scenarios of changes in agricultural policy and subsequent landscape impact for 2 rural regions within the Canton of Grisons, Switzerland. To this purpose, an optimization model at the farm level was combined with spatially explicit land use data and an assessment tool to measure changes in landscape structure. One of the major findings shows that in a liberalization scenario, the number of farms within the 2 study regions decreases by about $20 \%$ until 2015, and agriculturally used land declines as well (Figure 5).

For more information on the 4 projects, see www.nfp48.ch

instance, such computer visualization effectively demonstrated that the planned visitor center for the Swiss National Park would cover the line of sight to the historical chateau in Zernez, Canton of Grisons (Figure 2). This had not been obvious before, either from the 3D cardboard model or from the in-situ profiles. As a result, the new center was realized at a different location, leaving the surroundings of the historical building complex untouched.

Once the required input data are available and the system is set up, computer-generated visualization also drastically reduces the time needed to create images of alternative scenarios. Not only "real world" data can be used as inputs for such visualization: the numerical output of a model can also be transferred directly into a photorealistic representation based on this technique.

\section{Modeling in landscape planning}

The user-friendliness and number of model-based tools for planning are consider- ably lower compared to visualization tools. Still, also in the area of modeling, we find computer-based tools. One example is RiskPlan at the Swiss Federal Office for the Environment (FOEN) and the Swiss Federal Office for Civil Protection (FOCP). This is a strongly simplified risk analysis tool that provides first-order support for decision-making in risk and natural hazard management. Another example, partly enhanced within the NRP48, is the protection forest model by Peter Brang of the Swiss Federal Institute for Forest, Snow and Landscape Research (WSL), a tool to optimize the protection function of mountain forests against rockfall. These applications are niche products addressing very specific and well-defined tasks.

However, in landscape planning the complexity of decisions is often high and encompasses multiple, interdependent aspects, such as land use, economy, biodiversity, and recreation potential. When multiple aspects of the landscape have to be combined in practical planning, model-based tools are hardly used. One of the 
main reasons is that the interfaces between different modules within such a multidisciplinary model are hard to calibrate and often include many assumptions. This, of course, makes it difficult to elaborate transferable, ready-to-use tools.

Another reason is that most landscape models to date have been developed within a research environment. The outcome of a research project, however, is hardly ever a fully operational tool. It would require software developers and special techniques to actually produce such tools. One possible and promising technique could be the formulation of "use cases." "Use cases" consist of small narratives that reproduce the users' requirements in great detail, and break them down into a number of small individual tasks requested from the computer applications. The generation of "use cases" is, among other things, a technique for improving communication between the actual user of a tool and its developer. Although they have been used for many years in software development, they have hardly ever been applied in landscape planning.

Apart from applying fully operational tools, modeling can also be considered as a sophisticated method to analyze existing or newly surveyed data in a planning process. For instance, the extrapolation of an observed trend might not fully reflect the expected development. But a simple model can already give a better estimate of future development.

\section{Implementing models in planning: potentials and current limitations}

The following examples based on NRP48 models (Box 2) serve to highlight the potential of state-of-the-art research, and to demonstrate the problems in developing highly complex operational tools.

\section{Example 1: Agricultural change and tourism attractiveness}

One eminent question that arises in discussions about landscape conservation in the Alps tackles the consequences of agricultural change for Alpine tourist regions. To address this question, it appears logical

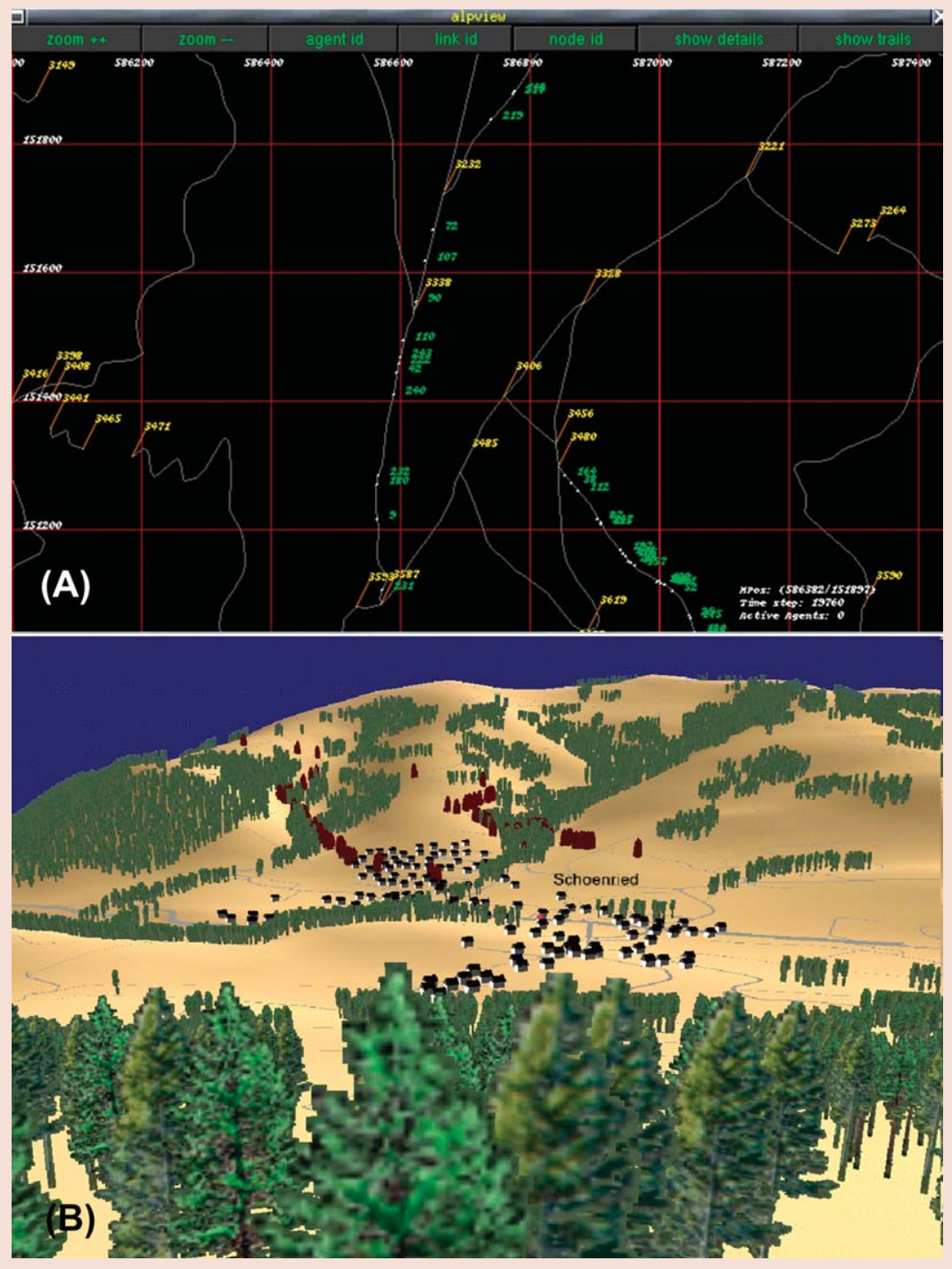

to hypothetically combine the highly complementary NRP48 modeling projects briefly introduced in Box 2.

Thus, SULAPS could hypothetically simulate the reaction to changing agricultural policies at the level of individual farms and output spatially explicit landuse changes as well as changes in agricultural productivity. ALPSCAPE would then approximate the economic effects of changing agricultural production on the local economy and resource management. Further, IPODLAS would simulate forest growth on abandoned land, based on empirically derived growth curves. Then ALPSIM would focus on changing hiking patterns, recreational behavior, tourist satisfaction, and the number of days spent at the holiday destination as a response to landscape alteration. The changing number of days spent at the destinations could finally be fed back to the economic model
FIGURE 3 (A) shows the 2dimensional output produced by an ALPSIM simulation. It visualizes the movement of the agents (white dots) and agentrelated data, for example the agents' IDs (in green). (B) produces a more realistic, 3dimensional simulation. The agents are rendered at 10 times their natural size for better visibility. (Images courtesy of Duncan Cavens) 
FIGURE 4 IPODLAS user interface to calculate and visualize the migration of larch bud moth populations. (Screen shot by authors)

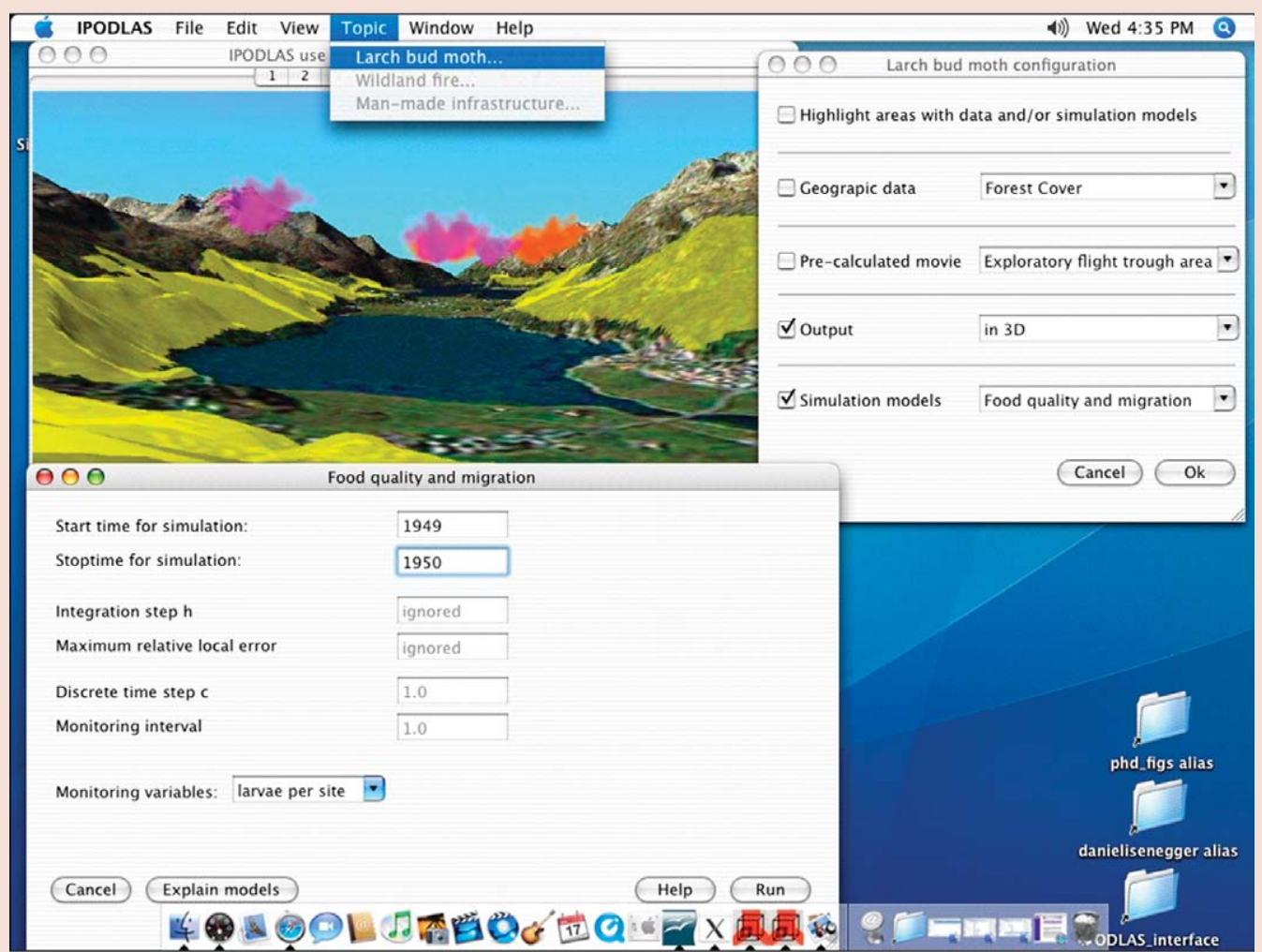

of ALPSCAPE to estimate the impact on the local economy.

Although this looks like an ideal coupling of the existing models and a great opportunity to fully exploit their potential, the technical and methodological challenges, particularly at the interfaces between models, are remarkable. Basic problems are (1) the limited exchangeability of data (content, scale, extent, purpose, validity range, etc) among the models, (2) implicit assumptions often closely connected to the modeling techniques and algorithms, including temporal and spatial scales of validity, and (3) the increase in uncertainties which add up with the number of models that are consecutively used.

\section{Example 2: Animation of hikers' behavior in the vicinity of the proposed Schatzalp Tower}

In the second example, the ALPSIM model (Box 2) was transferred to the municipality of Davos to assess the effect of the proposed Schatzalp Tower (Box 1) on hikers' behavior. Based on the primary input data on topography, land cover, and the tower itself, the ALPSIM model ran simu- lations and produced an animation as a key visualization product (see Figure 5). Although no special adjustments, eg in agents' behavior, or extra data surveys were accomplished, the preparation of the input data, the simulation runs and the production of the animation totaled up to 37 workdays.

This example shows that the model can technically be transferred to a different setting, but the effort involved and the lack of user-friendliness are still major problems. If such models are to be established as easy-to-use tools in planning, the availability of the required input data needs to be ensured; and convenience in operational application, including transfer to other regions, would still have to improve significantly.

\section{Developing better planning tools}

Modeling and visualization in landscape research and in planning practice do not have much in common these days. But with regard to the ongoing alteration of the Alpine landscape, planners and decision-makers should profit more from the 


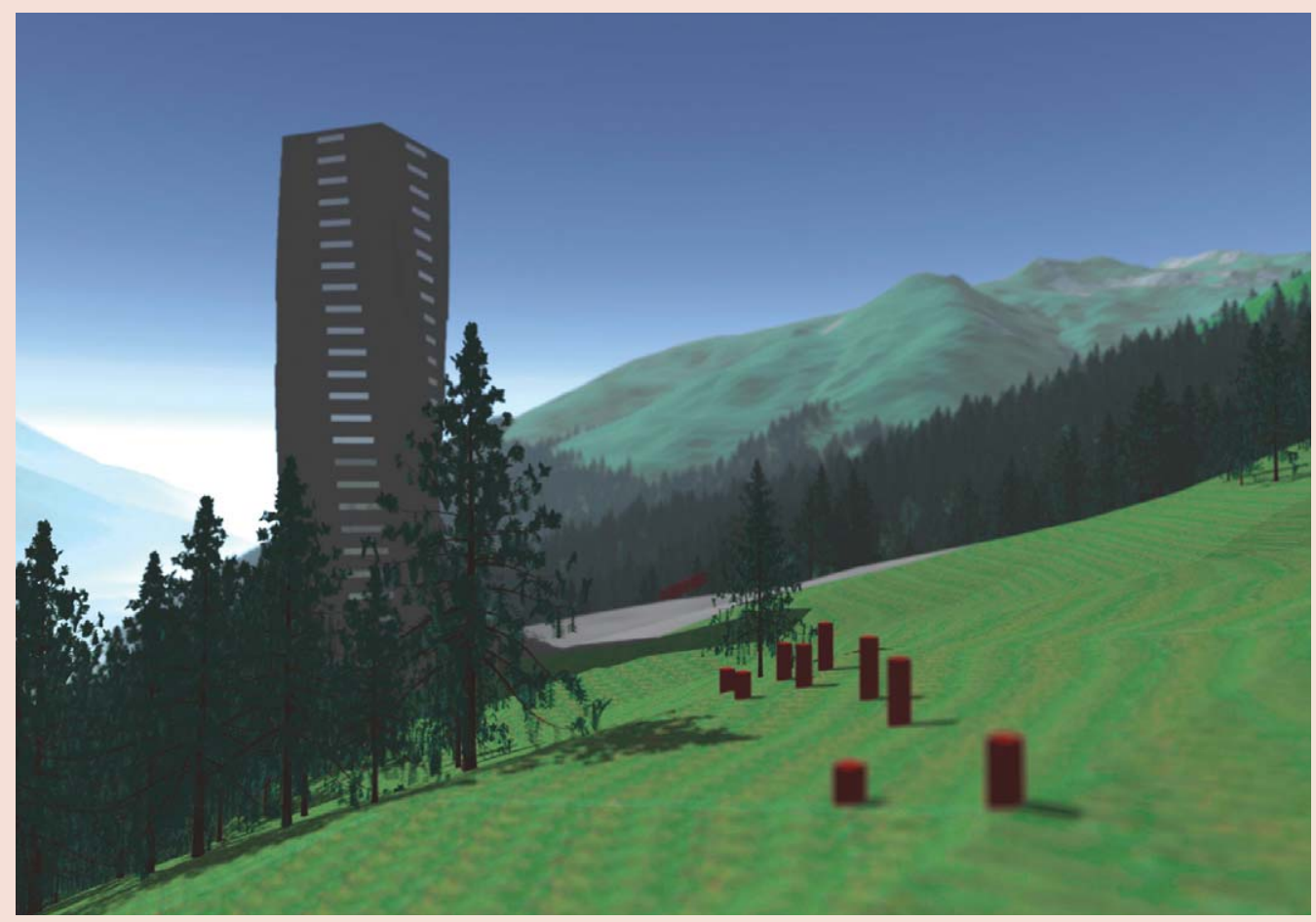

great potential of state-of-the-art modeling and visualization.

While computer-based visualization is increasingly used in planning processes, the application of models is still rare. The outputs of the research community represent mostly prototype models for specific case studies. They are too complex to be easily transferred and often too time- and labor-intensive in their application.

To get beyond the development of such prototypes, and to establish tools for practical planning, the models would need to focus on similarities in regularly arising planning questions. They would need to encounter a degree of detail that is required to add to the "real world" problem, and at the same time

\section{FURTHER READING}

Brang P. Schutzwaldmodell. Projektinformationen. Swiss Federal Institute for Forest, Snow and Landscape Research. http://www.wsl.ch/forschung/

forschungsprojekte/schutzwaldmodell; accessed on 11 December 2007.

Lauber S. 2006. Path-dependent change in agricultural structure in two mountain areas in Switzerland. A spatially explicit modelling approach. In: Mann S, editor. Causes and Impacts of Agricultural Structures. New York: Nova Science still allow for transfer to different regions. And the operability and userfriendliness of these models would need to be improved. Although the research community, and also the NRP48, can contribute to such tools with many findings and methodological advances, the actual elaboration of a model-based tool for operational use might be better accomplished by software developers. Still, when looking at the course that landscape visualization has taken over the last 20 years, one can speculate that landscape modeling will also eventually make it into the planning mainstream. This would certainly improve the knowledge base for the fundamental decisions that need to be taken with regard to the Alps in the near future.

Publishers, pp 77-97.

Swiss Federal Office for the Environment, Swiss Federal Office for Civil Protection. 2008. RiskPlan2. A Tool for Pragmatic Risk Management. http://www.riskplan.ch; accessed on 13 March 2008.

Walz A, Gloor C, Bebi P, Fischlin A, Lange E, Nagel K, Allgöwer B. 2008. Virtual Worlds-Real Decisions? The Alps in a Modeller's Nutshell. Synthesis V on "Virtual representation" of the National Research Programme NRP48 on "Landscapes and Habitats in the Alps." Zurich, Switzerland: vdf.
FIGURE 5 Visualization of the planned Schatzalp Tower, Davos, Canton of Grisons, Switzerland and its Alpine setting. (Image by authors)

\section{AUTHORS}

\section{Ariane Walz, Peter Bebi}

WSL-Swiss Federal Institute for Snow and Avalanche Research SLF, Flüelastrasse 11, 7260 Davos, Switzerland. walz@slf.ch; bebi@slf.ch

Ariane Walz is a geographer who did her doctoral research on land use change modeling within an integrated approach to regional development, within the NRP48 project ALPSCAPE.

Peter Bebi is an environmental scientist with a special focus on mountain forests and interdisciplinary research (director of ALPSCAPE).

\section{Britta Allgöwer, Christian Gloor} Geography Department, GIS Division, University of Zurich, Winterthurer Strasse 190, 8057 Zurich, Switzerland.

britta@geo.unizh.ch; chgloor@geo.unizh.ch

Britta Allgöwer is a senior research scientist with a special focus on nature conservation, GIS, and disturbance dynamics research (director of IPODLAS).

Christian Gloor is a computer scientist who did his doctoral research within the ALPSIM project on distributed intelligence in Multi-Agent Systems.

\section{Andreas Fischlin}

Terrestrial Systems Ecology, Swiss Federal Institute of Technology (ETHZ), 8092 Zurich, Switzerland. andreas.fischlin@env.ethz.ch

Andreas Fischlin is a biologist with a strong focus on ecosystem and climate change modeling (co-director of IPODLAS). He was “Coordinating Lead Author" of the second book of the 4th United Nations Climate Report, produced by the IPCC, which won the 2007 Nobel Peace Prize award together with Al Gore.

\section{Eckart Lange}

Department of Landscape, University of Sheffield, Floor 3, Arts Tower, Western Bank, Sheffield S10 2TN, United Kingdom.

e.lange@sheffield.ac.uk

Eckart Lange is a landscape planner with a strong focus on visualization and participation for environmental decision-making (co-director of ALPSIM).

\section{Kai Nagel}

Department of Mechanical and Transport Engineering, TU Berlin, D-10587 Berlin, Germany. nagel@vsp.tu-berlin.de

Kai Nagel is a physicist and computer scientist with considerable expertise in complex systems modeling (co-director of ALPSIM). 